\title{
Antenatal treatment in two Dutch families with pyridoxine-dependent seizures
}

\author{
Levinus A. Bok • Jasper V. Been • Eduard A. Struys • \\ Cornelis Jakobs • Elisabeth A. M. Rijper • \\ Michèl A. Willemsen
}

Received: 9 March 2009 / Accepted: 15 June 2009 /Published online: 9 July 2009

(C) Springer-Verlag 2009

\begin{abstract}
Incidental reports suggest that antenatal treatment of pyridoxine dependent seizures (PDS) may improve neurodevelopmental outcome of affected patients. Two families with PDS are reported, both with two affected siblings. Antenatal treatment with pyridoxine was instituted during the second pregnancy in each family (50 and $60 \mathrm{mg}$ daily from 3 and 10 weeks of gestation, respectively). Perinatal characteristics and neurodevelopmental outcome at 4 (Family A) and 12 (Family B) years of age were compared between the untreated and treated child within each family. Meconium-stained amniotic fluid was present in both first pregnancies and abnormal foetal movements
\end{abstract}

L. A. Bok $(\square)$

Department of Paediatrics, Máxima Medical Centre,

P.O. Box 7777, 5500 MB Veldhoven, The Netherlands

e-mail: 1.bok@mmc.nl

J. V. Been

Department of Paediatrics, Maastricht University Medical Centre,

Maastricht, The Nethe?rlands

E. A. Struys $\cdot$ C. Jakobs

Metabolic Unit, Department of Clinical Chemistry,

VU University Medical Center Amsterdam,

Amsterdam, The Netherlands

E. A. M. Rijper

Department of Pediatric Psychology, Máxima Medical Centre,

Veldhoven, The Netherlands

M. A. Willemsen

Department of Paediatric Neurology,

Radboud University Nijmegen Medical Centre,

Nijmegen, The Netherlands

\section{A. Willemsen}

Donders Institute for Brain, Cognition and Behaviour,

Radboud University,

Nijmegen, The Netherlands were noticed in one. In the treated infants, pregnancy and birth were uncomplicated. In family A, postnatal pyridoxine supplementation prevented neonatal seizures. Both children in family $\mathrm{A}$ were hypotonic and started walking after 2 years of age; both had white matter changes on MRI, and the first child was treated for squint. IQ was 73 and 98 in the antenatally untreated and treated child, respectively. The second child in family B developed seizures on the seventh day, because pyridoxine maintenance therapy had not been instituted after birth. Seizures responded rapidly to pyridoxine supplementation. MRI showed large ventricles and a mega cisterna magna. IQ was 80 and 106 in the antenatally untreated and treated child respectively. Both children had normal motor development. These results suggest that antenatal pyridoxine supplementation may be effective in preventing intrauterine seizures, decreasing the risk of complicated birth and improving neurodevelopmental outcome in PDS.

Keywords Seizures · Pyridoxine - Antenatal treatment . Development

\section{Introduction}

Pyridoxine-dependent seizures (PDS; MIM 266100) is a rare autosomal recessive disorder with an estimated birth incidence between one in 396,000 [7] and one in 783,000 [4]. PDS has been recognised for over 50 years since the first report by Hunt et al. in 1954 [17]. The classic presentation of PDS consists of neonatal seizures that are intractable to conventional anti-epileptic drugs but adequately respond to pyridoxine (vitamin B6) administration. In retrospect, about $20 \%$ of mothers report abnormal foetal movements highly suggestive of intrauterine seizures [16]. 
Birth can be complicated, as a third of the children present with asphyxia and/or suspected hypoxic-ischaemic encephalopathy $[4,16]$. Not only is PDS characterised by seizures but also by encephalopathic symptoms such as agitation, jitteriness, irritability, startle reactions and feeding problems [16]. Reports on cerebral imaging have shown cerebral haemorrhage, non-specific white matter abnormalities, hydrocephalus, hypoplasia of the posterior part of the corpus callosum, cerebellar hypoplasia and a megacisterna magna $[5,15,19,33]$. At older age, cortical atrophy with ventricular dilation is sometimes observed in affected patients $[5,15,34]$.

Until recently, PDS was a clinical diagnosis based upon effective seizure control by pyridoxine administration. In 2006, mutations in the ALDH7A1 gene were shown to be present in the majority of patients with a clinical diagnosis of PDS [20, 24, 29, 31]. ALDH7A1 encodes the enzyme $\alpha$ aminoadipic semialdehyde ( $\alpha$-AASA) dehydrogenase that plays a role in the degradation of the amino acid lysine. $\alpha$ AASA dehydrogenase deficiency leads to increased levels of $\alpha$-AASA in urine and plasma [24], and $\alpha$-AASA can, therefore, be used as a biomarker for PDS [10] There are at least two pathophysiological mechanisms that play a role in PDS. First, semi-aldehydes easily bind to many different molecules, and accumulation of $\alpha$-AASA might, therefore, have toxic effects on the (developing) central nervous system. Second, $\alpha$-AASA is non-enzymatically converted to L-delta(1)-piperideine-6-carboxylate, which is a metabolite that binds pyridoxal-5-phosphate (the active B6 vitamer) and as such leads to secondary pyridoxal-5phosphate deficiency [24].

Despite successful seizure control with pyridoxine substitution, the majority of surviving PDS patients shows some degree of cognitive impairment, particularly concerning expressive language development. Only around $20 \%$ of treated PDS patients are described as having a normal development $[14,16]$. Reports of a possible relationship between treatment delay and cognitive impairment have been inconsistent $[6,7]$. Incidental reports of antenatal treatment with pyridoxine in a second pregnancy suggest that this approach may be effective in controlling intrauterine seizures [8] and may improve developmental outcome [8, 17, 18, 25, 28, 30, 32]. However, only eight cases of antenatal pyridoxine supplementation have been described, and with limited follow-up. Furthermore, treatment sometimes only coincidentally aimed for multi-vitamin supplementation in low doses and for a limited number of months. The importance of long-term follow-up is illustrated by reports of PDS patients showing an average development initially, though not based on a formal assessment but experiencing developmental delays at a later stage $[6,22,23]$.
We report two PDS families from the Dutch PDS cohort with long-term follow-up after antenatal treatment in a second pregnancy.

\section{Methods and patients}

Currently, the Dutch PDS cohort comprises 14 living children (born 1991-2007), including three families with two PDS patients each. In two of these families, the mother used pyridoxine daily during the second pregnancy from the first trimester onwards. Methodology and results of $\alpha$ AASA measurements and ALDH7A1 mutation analysis have previously been reported $[10,31]$. Table 1 presents patient data on the clinical course, imaging and outcome.

\section{Case reports}

Family A, Child 1 A girl was born at term with meconiumstained amniotic fluid and Apgar scores of 7 and 8 after 1 and $5 \mathrm{~min}$, respectively. She developed clinical seizures within $1 \mathrm{~h}$ after birth. Initially, seizures were temporarily controlled by phenobarbitone and clonazepam. Pyridoxine $50 \mathrm{mg}$ was administered intravenously when seizures recurred on the fourth day of life; after this, seizures ceased within $5 \mathrm{~min}$. Subsequently, the girl became hypotonic and needed respiratory support for 2 days. All anti-epileptic drugs were discontinued after administration of pyridoxine, and no maintenance therapy with pyridoxine was instituted. Seven days after the initial administration of pyridoxine, generalised seizures recurred. Again, seizures responded to parenteral administration of pyridoxine. The girl was diagnosed with probable PDS (patient 10 [7]) according to the clinical criteria of Baxter [4], and maintenance monotherapy with pyridoxine $15 \mathrm{mg} / \mathrm{kg} /$ day was instituted. In retrospect, the mother reported abnormal jerky foetal movements highly suggestive of intrauterine seizures. MRI of the brain on the fifth day of life showed multiple bilateral lesions in the white matter on T2, corresponding with cerebral oedema. Diffusion-weighted images showed in general an increased apparent diffusion coefficient (ADC) with numerous focal lesions with a decreased ADC, corresponding with a structural abnormal cerebral white matter and recent cytotoxic lesions containing increased extracellular water. At the age of 5 months, a second MRI showed a thin corpus callosum and slight asymmetric ventriculomegaly without clear white matter abnormalities. At 3 years of age (in 2006), the diagnosis of PDS was proven at the metabolic and DNA level (Table 1). At the time of this report, the child is 5 years of age and seizure-free on pyridoxine monotherapy. She is hypotonic and has motor dyspraxia. In addition, she was treated for squint and did not walk until the age of 2.75 years. Mental development according to the Snijders-Oomen Nonverbal 


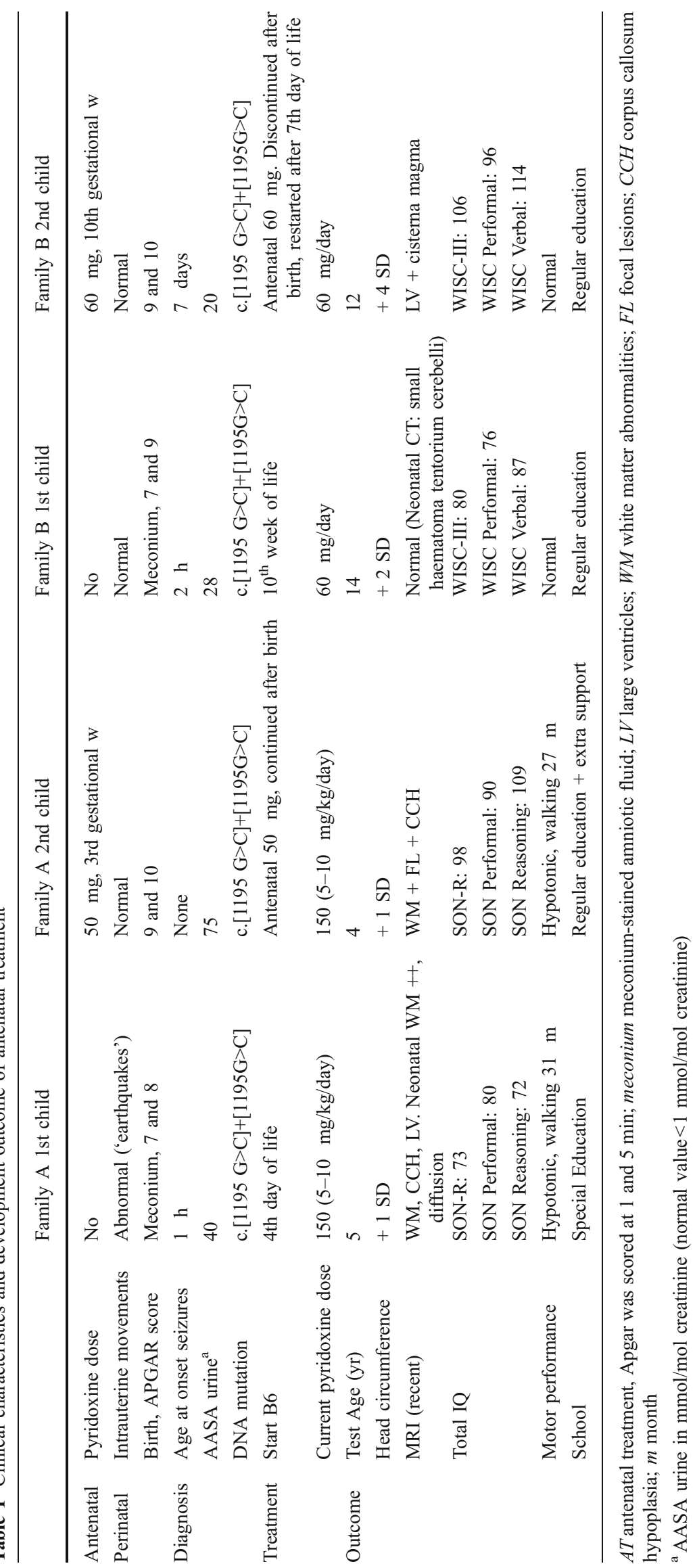


Intelligence Test (SON-R) [26] is below average, particularly in expressive language skills (Table 1). For these reasons, she currently attends a school for special education.

Family A, Child 2 During the second pregnancy of a son, the mother used pyridoxine $50 \mathrm{mg} /$ day from the third week of gestation. Pregnancy and birth, as well as the neonatal period, were uneventful. From the first day of life, pyridoxine supplementation $50 \mathrm{mg} /$ day was instituted which was increased to $150 \mathrm{mg} /$ day at 6 months of age. In the first year of life, no seizures were noticed; at age 1 year, the child experienced a febrile convulsion twice. At 1.5 years of age (in 2006), PDS was proven at the metabolic and DNA level (Table 1). At the age of 4 years, he had a right-sided hemi status epilepticus during a febrile period with diarrhoea, which was controlled after $200 \mathrm{mg}$ pyridoxine administered intravenously. MRI of the brain at age 1.5 years showed bilateral white matter abnormalities and a thin genu corpus callosum. He started walking at age 2.25 years. At the present age of 4 years, he is slightly hypotonic. His mental development, assessed using the SON-R, is average, although there is a delay in expressive language skills, needing extra support. His MRI still shows circumscript bilateral frontal white matter abnormalities. The parents have no other children and have an average social economic status.

Family B, Child 1 The first child in this family, a girl, was born with meconium-stained amniotic fluid. She developed seizures $2 \mathrm{~h}$ after birth. Pyridoxine $60 \mathrm{mg} /$ day was started after the 10th week of life when trials with several antiepileptic drugs had failed to control her seizures [36]. Ultrasound and CT scan of the brain showed no cerebral abnormalities, except for a small haematoma of the tentorium cerebelli. A trial of withdrawal was never performed and at 12 years of age PDS was proven at the metabolic and DNA level (Table 1). At the moment of this report, the child is 14 years old, attends a regular school and has a normal motor development. A recent MRI of her brain showed no abnormalities.

Family B, Child 2 The mother used $60 \mathrm{mg}$ pyridoxine daily during her second pregnancy from the 10th week of gestation onwards. Pregnancy and birth were uncomplicated. Erroneously no pyridoxine maintenance therapy was instituted after birth. The boy developed seizures on the seventh day of life, after which, treatment was started with $60 \mathrm{mg}$ pyridoxine daily. Consequently, seizures were controlled. At 10 years of age, PDS was proven at the metabolic and DNA level (Table 1). The boy is currently doing well and shows no abnormalities on neurological examination; he attends a regular school and has a normal motor development. MRI of the brain at age 12 years showed slightly enlarged lateral ventricles and some enlargement of the cisterna magna with a normal corpus callosum. Table 1 presents data on the mental development of these children using the WISC-III [21]. The parents have no other children and have an average social economic status.

\section{Discussion}

In this report on antenatal treatment in PDS, the first child was regarded as the 'natural' control patient of the antenatally treated second PDS patient in that same family. Pyridoxine was well tolerated by the mother, and no abnormal foetal movements were reported in the antenatally treated PDS patients. Moreover, pregnancy, labour and birth were uncomplicated after antenatal treatment with pyridoxine. These observations suggest that antenatal treatment of PDS may be an effective treatment to prevent intrauterine seizures and reduce birth-related complications [16].

Within each family, the same intelligence test was used to compare the sibs. In family A, a non-verbal developmental test (SON-R) was used because this test has sound psychometric properties and is often used for children with speech problems, as was the case for these children. In the second family, the WISC-III was used, which measures both verbal and non-verbal capacities and is often used to determine intellectual capabilities of children attending regular education. The antenatally treated children in both families were shown to have better test results than their first-born sibs. This suggests that antenatal pyridoxine treatment may improve mental development, although some degree of developmental delay remained in the second child of family A. We were not able to compare the outcomes of the affected children to healthy nonaffected siblings, since there were none for both families. All four parents have attended regular education.

Interestingly, in family $\mathrm{B}$, the first child developed clinical seizures $2 \mathrm{~h}$ after birth, whereas the second child developed clinical seizures on the 7th day of life. In children with PDS who stop pyridoxine treatment, seizure recurrence is usually reported within $5-7$ days $[6,16]$, suggesting a pyridoxine 'storage' sufficient to temporarily prevent seizure occurrence in these patients. These observations further suggest that in the present study, the second child was adequately treated antenatally and that the pyridoxine dose prevented seizures shortly after birth. Conversely, seizure occurrence on day 7 could also reflect the different effect of withdrawal in neonates in whom seizure recurrence can be delayed by up to 6 weeks [6] This observation might indicate what the optimum pyridoxine dose might be during pregnancy. Hyperemesis gravidarum is treated with $50-100 \mathrm{mg}$ pyridoxine a day, 
which is well tolerated by both mother and foetus [6]. Others suggested a necessarily daily supplement of 2.5 to $10 \mathrm{mg}$ pyridoxine in all pregnant women and have shown that the pyridoxine state of the mother significantly affects the foetus [3, 11]. In general, only long-term use of pyridoxine in doses over $200-300 \mathrm{mg} /$ day is thought to lead to adverse effects, especially reversible sensory neuropathy, in healthy adults [27]. Based on these observations, we suggest that a daily dose of $50 \mathrm{mg}$ is safe for the mother and may prevent foetal seizures, complications at birth and early neonatal seizures in PDS patients.

In the present study, MRI of the brain showed abnormalities in three of the four reported children, including in the antenatally treated children. This observation is important and suggests that antenatal pyridoxine treatment does not guarantee normal brain development and that additional mechanisms (besides seizure-induced injury) may be involved in PDS patients. These may include either toxicity due to elevated levels of $\alpha$-AASA or the lack of metabolite(s) after the metabolic block, both of which may cause neuronal damage or changes irrespective of pyridoxine treatment. In that case, interventions to prevent or treat these metabolic changes in PDS patients should be investigated in order to improve future outcome in this group. The disappearance of the neonatal white matters abnormalities seen in patient 1 (Family A) has been interpreted by us as the result of seizure control.

This is one of the few reports focusing on antenatal treatment of anticipated or possible PDS in a second child, including long-term and case-controlled follow-up. Until now, antenatal treatment of PDS has been reported in only eight patients $[8,12,17,18,25,28,30,32]$, and two of these reports (regarding a family that moved from France to England) might overlap [25, 30]. The reports are not uniform regarding the daily antenatal doses, the period of antenatal treatment, the reason for treatment or the reported (side)effects (Table 2). No complications at birth and no neonatal seizures in the first week of life were reported for any of the treated patients. Only four patients were formally tested regarding development outcome, all of whom showed some degree of developmental delay. In the remaining four patients, developmental outcome was either roughly described as 'normal' $(n=3)$ or 'delayed' $(n=1)$. Only one report mentioned a control PDS sib who did not receive antenatal pyridoxine treatment; this report concluded that antenatal treatment does not improve outcome, although the antenatally treated children scored about $10 \mathrm{IQ}$ points higher than the PDS patient that did not receive antenatal pyridoxine [30].

Because of the autosomal recessive nature of PDS, the recurrence risk is $25 \%$ in consecutive pregnancies. The metabolic and genetic defect of PDS has recently been elucidated [24], which gives the opportunity for prenatal

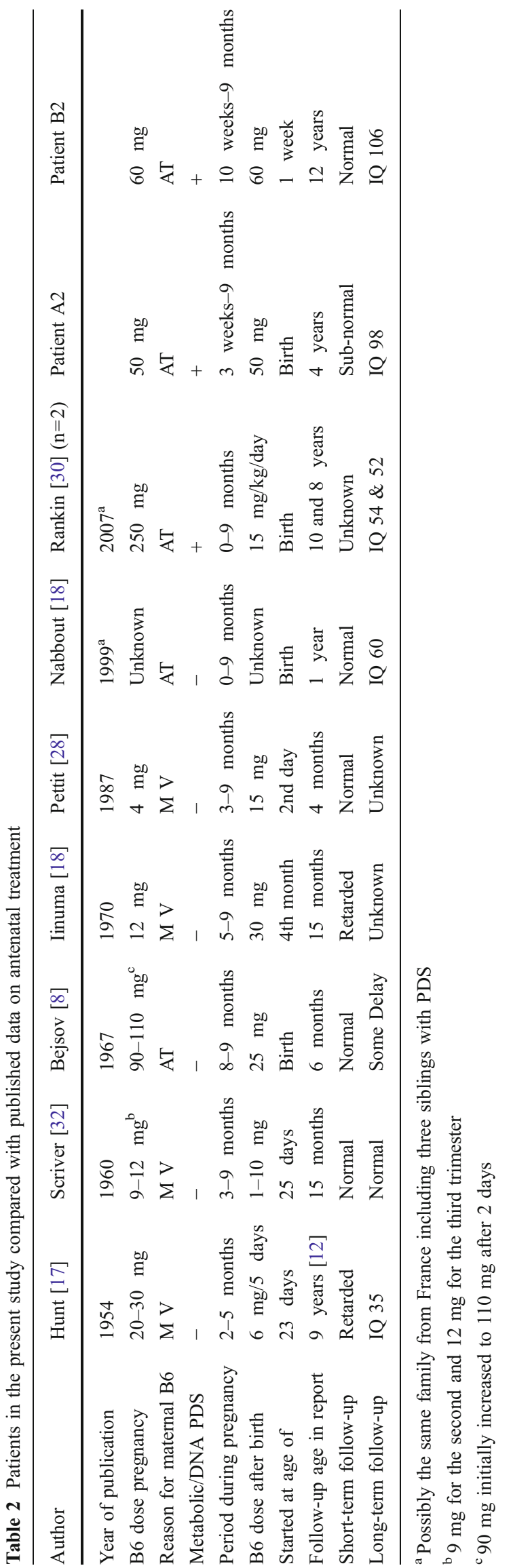


diagnostic investigation. In selected families, prenatal diagnosis and/or antenatal pyridoxine treatment can be offered. Antenatal pyridoxine treatment should start as early as possible in pregnancy and not be postponed until the results of eventual prenatal diagnostic tests are available.

In both families, the affected children were homozygous for the-common-c. $[1195 \mathrm{G}>\mathrm{C}]$ mutation, which has a relatively high frequency in the Netherlands (15 of 20 alleles [31]) and has also been frequently identified by others (12 of 36 alleles [29]; 11 of 30 alleles [9]). The mutation leads to substitution of glutamate at position 399 by glutamine (Glu399Gln) and is predicted to have a negative effect on the binding capacity of $\alpha$-AASA dehydrogenase to the required cofactor $\mathrm{NAD}^{+}$, resulting in decreased enzyme activity [35].

Intrauterine treatment of a foetus that suffers from a genetic metabolic disorder is rarely possible. Our report shows the possible positive effects that can be reached, and it aims to increase the awareness of clinicians regarding this 'unusual' treatment modality. Besides PDS, there are at least three other autosomal recessively inherited metabolic disorders that are good candidates for antenatal treatment. In 3-phosphoglycerate-dehydrogenase deficiency (a disorder of serine biosynthesis), supplementation of L-serine has been successful [13]. Vitamin B12-responsive methylmalonic aciduria can be treated by supplementation of the mother with high doses of vitamin B12 [1]. Finally, another defect of pyridoxine metabolism, namely pyridox(am)ine5 '-phosphate oxidase, should (at least theoretically) be treatable by supplementation of pyridoxal-5'-phosphate, the active form of pyridoxine [2]. The current study is limited by its retrospective nature and the small sample size, which is due to the rare nature of PDS. However, all previous reports on antenatal treatment are case reports, and most do not describe control patients. Prospective studies on the effects of antenatal treatment of PDS should be performed.

We conclude that after a previous child with PDS, there are strong arguments to supply mothers with pyridoxine during subsequent pregnancies. Using this approach, foetal and neonatal seizures and birth-related complications in affected sibs may be prevented. Finally, our data suggest that antenatal treatment may improve developmental outcome in subsequent PDS patients compared to untreated siblings.

Conflict of Interest All authors declare that they have no conflict of interest. This study was not financially sponsored.

\section{References}

1. Ampola MG, Mahoney MJ, Nakamura E, Tanaka K (1975) Prenatal therapy of a patient with vitamin-B12-responsive methylmalonic acidemia. N Engl J Med 293:313-317

2. Bagci S, Zschocke J, Hoffmann GF, Bast T, Klepper J, Muller A, Heep A, Bartmann P, Franz AR (2008) Pyridoxal phosphatedependent neonatal epileptic encephalopathy. Arch Dis Child Fetal Neonatal Ed 93:F151-F152

3. Baker H, Frank O, Deangelis B, Feingold S, Kaminetzky HA (1981) Role of placenta in maternal-fetal vitamin transfer in humans. Am J Obstet Gynecol 141:792-796

4. Baxter P (1999) Epidemiology of pyridoxine dependent and pyridoxine responsive seizures in the UK. Arch Dis Child 81:431-433

5. Baxter P, Griffiths P, Kelly T, Gardner-Medwin D (1996) Pyridoxine-dependent seizures: demographic, clinical, MRI and psychometric features, and effect of dose on intelligence quotient. Dev Med Child Neurol 38:998-1006

6. Baxter P (2001) Pyridoxine dependent and pyridoxine responsive seizures. In: Baxter $\mathrm{P}$ (ed) Vitamin responsive conditions in paediatric neurology. Mac Keith, London, pp 109-165

7. Been JV, Bok LA, Andriessen P, Renier WO (2005) Epidemiology of pyridoxine dependent seizures in the Netherlands. Arch Dis Child 90:1293-1296

8. Bejsovec M, Kulenda Z, Ponca E (1967) Familial intrauterine convulsions in pyridoxine dependency. Arch Dis Child 42:201-207

9. Bennett CL, Chen Y, Hahn S, Glass IA, Gospe SM Jr (2008) Prevalence of ALDH7A1 mutations in 18 North American pyridoxine-dependent seizure (PDS) patients. Epilepsia 50 (5):1167-1175

10. Bok LA, Struys E, Willemsen MA, Been JV, Jakobs C (2007) Pyridoxine-dependent seizures in Dutch patients: diagnosis by elevated urinary alpha-aminoadipic semialdehyde levels. Arch Dis Child 92:687-689

11. Cleary RE, Lumeng L, Li TK (1975) Maternal and fetal plasma levels of pyridoxal phosphate at term: adequacy of vitamin B6 supplementation during pregnancy. Am J Obstet Gynecol 121:25-28

12. Coursin DB (1964) Vitamin B6 metabolism in infants and children. Vitam Horm 22:755-786

13. de Koning TJ, Klomp LW, van Oppen AC, Beemer FA, Dorland L, van der Berg I, Berger R (2004) Prenatal and early postnatal treatment in 3-phosphoglycerate-dehydrogenase deficiency. Lancet 364:2221-2222

14. Gospe SM (2002) Pyridoxine-dependent seizures: findings from recent studies pose new questions. Pediatr Neurol 26:181-185

15. Gospe SM Jr, Hecht ST (1998) Longitudinal MRI findings in pyridoxine-dependent seizures. Neurology 51:74-78

16. Haenggeli CA, Girardin E, Paunier L (1991) Pyridoxinedependent seizures, clinical and therapeutic aspects. Eur J Pediatr 150:452-455

17. Hunt AD Jr, Stokes J Jr, McCrory WW, Stroud HH (1954) Pyridoxine dependency: report of a case of intractable convulsions in an infant controlled by pyridoxine. Pediatrics $13: 140-145$

18. Iinuma K, Narisawa K, Yamauchi N, Yoshida T, Mizuno T (1971) Pyridoxine dependent convulsion: effect of pyridoxine therapy on electroencephalograms. Tohoku J Exp Med 105:19-26 
19. Jardim LB, Pires RF, Martins CE, Vargas CR, Vizioli J, Kliemann FA, Giugliani R (1994) Pyridoxine-dependent seizures associated with white matter abnormalities. Neuropediatrics 25:259-261

20. Kanno J, Kure S, Narisawa A, Kamada F, Takayanagi M, Yamamoto K, Hoshino H, Goto T, Takahashi T, Haginoya K, Tsuchiya S, Baumeister FA, Hasegawa Y, Aoki Y, Yamaguchi S, Matsubara Y (2007) Allelic and non-allelic heterogeneities in pyridoxine dependent seizures revealed by ALDH7A1 mutational analysis. Mol Genet Metab 91:384-389

21. Kort W, Schittekatte M, Dekker PH et al (2005) WISC-III NL; Wechsler intelligence scale for children, derde Editie NL. Harcourt Test, London

22. Kroll JS (1985) Pyridoxine for neonatal seizures: an unexpected danger. Dev Med Child Neurol 27:377-379

23. Lott IT, Coulombe T, Di Paolo RV, Richardson EP Jr, Levy HL (1978) Vitamin B6-dependent seizures: pathology and chemical findings in brain. Neurology 28:47-54

24. Mills PB, Struys E, Jakobs C, Plecko B, Baxter P, Baumgartner M, Willemsen MA, Omran H, Tacke U, Uhlenberg B, Weschke B, Clayton PT (2006) Mutations in antiquitin in individuals with pyridoxine-dependent seizures. Nat Med 12:307-309

25. Nabbout R, Soufflet C, Plouin P, Dulac O (1999) Pyridoxine dependent epilepsy: a suggestive electroclinical pattern. Arch Dis Child Fetal Neonatal Ed 81:F125-F129

26. Tellegen PJ, Winkel M, Wijnberg-Williams BJ et al (1998) Snijders-Oomen Niet-verbale Intelligentietest, SON-R 21/2-7. Swets \& Zeitlinger B.V., Lisse

27. Parry GJ, Bredesen DE (1985) Sensory neuropathy with low-dose pyridoxine. Neurology 35:1466-1468

28. Pettit RE (1987) Pyridoxine dependency seizures: report of a case with unusual features. J Child Neurol 2:38-40
29. Plecko B, Paul K, Paschke E, Stoeckler-Ipsiroglu S, Struys E, Jakobs C, Hartmann H, Luecke T, di Capua M, Korenke C, Hikel C, Reutershahn E, Freilinger M, Baumeister F, Bosch F, Erwa W (2007) Biochemical and molecular characterization of 18 patients with pyridoxine-dependent epilepsy and mutations of the antiquitin (ALDH7A1) gene. Hum Mutat 28:19-26

30. Rankin PM, Harrison S, Chong WK, Boyd S, Aylett SE (2007) Pyridoxine-dependent seizures: a family phenotype that leads to severe cognitive deficits, regardless of treatment regime. Dev Med Child Neurol 49:300-305

31. Salomons GS, Bok LA, Struys EA, Pope LL, Darmin PS, Mills PB, Clayton PT, Willemsen MA, Jakobs C (2007) An intriguing "silent" mutation and a founder effect in antiquitin (ALDH7A1). Ann Neurol 62:414-418

32. Scriver CR (1960) Vitamin B6-dependency and infantile convulsions. Pediatrics 26:62-74

33. Shih JJ, Kornblum H, Shewmon DA (1996) Global brain dysfunction in an infant with pyridoxine dependency: evaluation with EEG, evoked potentials, MRI, and PET. Neurology 47:824-826

34. Tanaka R, Okumura M, Arima J, Yamakura S, Momoi T (1992) Pyridoxine-dependent seizures: report of a case with atypical clinical features and abnormal MRI scans. J Child Neurol 7:24-28

35. Tang WK, Wong KB, Lam YM, Cha SS, Cheng CH, Fong WP (2008) The crystal structure of seabream antiquitin reveals the structural basis of its substrate specificity. FEBS Lett 582:3090 3096

36. van Waarde WM, Tummers RF, Bosschaart AN, Hageman G (1995) Pyridoxine-dependent epilepsy in an infant. Ned Tijdschr Geneeskd 139:1694-1697 